CATAFESTA, Manuela; BORTOLI, Fábio. O Edifício Formac pelas lentes de João Alberto Fonseca da Silva. Thésis, Rio de Janeiro, v. 5 , n. 9 , p. $107-125$, nov. 2020

data de submissão: $15 / 08 / 2020$

data de aceite: $19 / 11 / 2020$

\section{O Edifício Formac pelas lentes de João Alberto Fonseca da Silva ${ }^{1}$ Manuela Catafesta, Fábio Bortoli}

Manuela CATAFESTA é Doutora em Arquitetura; Centro Universitário Ritter dos Reis - UniRitter; manuela_catafesta@uniritter.edu.br

Fábio BORTOLI é Doutor em Arquitetura; Centro Universitário Ritter dos Reis - UniRitter, fabio_bortoli@uniritter.edu.br

\section{Resumo}

1 Versão ampliada e revisada do trabalho apresentado no VI Seminário Docomomo Sul, 2019. CATAFESTA, Manuela; BORTOLI, Fábio. O Edifício Formac pelas lentes de João Alberto Fonseca da Silva. em Anais do VI Seminário Docomomo Sul [recurso eletrônico] : o moderno e reformado / Carlos Eduardo Comas, Marta Peixoto (organizadores). Porto Alegre : Marcavisual , 2019.

O propósito deste artigo é ampliar o debate sobre a história da fotografia no Rio Grande do Sul, mais especificamente sobre a prática da fotomontagem no campo da arquitetura, tendo em vista os raros estudos nessa área. A fotomontagem foi a modalidade de expressão capaz de ilustrar as novas possibilidades de simulação das transformações pelas quais a capital gaúcha passaria na década de 1950. Em Porto Alegre, o primeiro fotógrafo a utilizar a técnica da fotomontagem na arquitetura foi João Alberto Fonseca da Silva que, mesmo sendo autodidata, pode ser considerado um visionário na arte de fotografar. João Alberto utilizou essa técnica pioneiramente no Edifício Formac (1952), a partir da encomenda do arquiteto Carlos Alberto Holanda Mendonça. O objetivo do arquiteto era ilustrar, em etapa de projeto, a inserção do edifício em seu contexto, em um período em que a capital gaúcha passava por um notável processo de verticalização urbana. O artigo se vale da coleta, análise e divulgação de material de acervo, composto pelas etapas da fotomontagem e fotografias da construção do edifício Formac, que foi doado ao Centro Universitário Ritter dos Reis pelo próprio fotógrafo, e que configura um importante registro da história da fotografia e da arquitetura gaúcha e brasileira, além de herança cultural sem precedentes no Rio Grande do Sul. Com isso, se espera colaborar para a divulgação do acervo fotográfico de João Alberto e para o entendimento de sua produção. A fotomontagem do Formac, que ainda hoje chama atenção pela qualidade técnica, expressividade e precisão, foi um elemento importante para a divulgação da nascente arquitetura moderna no contexto local.

Palavras-chave: João Alberto Fonseca da Silva, Edifício Formac, Carlos Alberto Holanda Mendonça, arquitetura moderna, fotografia.

\begin{abstract}
The purpose of this article is to expand the debate on the history of photography in the Rio Grande do Sul, more specifically on the practice of photomontage in architecture, because of the rare studies in this area. The photomontage was the new form of expression to simulate the transformations that the capital of Rio Grande do Sul would pass in the 1950s. In Porto Alegre, the first photographer to use the photomontage in architecture was João Alberto Fonseca da Silva who, even self-taught, can be considered a visionary in photography. João Alberto used this technique in the Formac Building (1952), by order of the architect Carlos Alberto Holanda Mendonça. The architect's objective was to illustrate the insertion of the building in its context when the capital of Rio Grande do Sul went through a remarkable process of urban verticalization. The analysis and dissemination of the collection material - which was donated to the Centro Universitário Ritter dos Reis by the photographer himself - contains the photomontage and photographs of the construction of the Formac Building and it
\end{abstract}


is an important part of the history of photography and architecture in the Rio Grande do Sul and in Brazil. Also, it is an unprecedented cultural heritage and we hope to collaborate with the dissemination and analysis of João Alberto's collection. The photomontage of the Formac Building, which still stands out today for its technical quality, expressiveness, and precision, was an important element for the dissemination of modern architecture then emerging in the local context.

Keywords: João Alberto Fonseca da Silva, Formac Building, Carlos Alberto Holanda Mendonça, modern architecture, photography.

\section{Resumen}

El propósito de este artículo es ampliar el debate sobre la historia de la fotografía en Rio Grande do Sul, más específicamente sobre la práctica del fotomontaje en el campo de la arquitectura, en vista de los escasos estudios en esta área. El fotomontaje fue la nueva forma de expresión capaz de ilustrar las nuevas posibilidades de simulación de las transformaciones que experimentaría la capital de Rio Grande do Sul en la década de 1950. En Porto Alegre, el primer fotógrafo en utilizar la técnica del fotomontaje en arquitectura fue João Alberto Fonseca da Silva quien, a pesar de ser autodidacta, se le puede considerar un visionario en el arte de la fotografía.João Alberto fuepioneroen esta técnica en el Edificio Formac (1952), por encargo del arquitecto Carlos Alberto Holanda Mendonça. El objetivo del arquitecto era ilustrar, en la etapa de diseño, la inserción del edificio en su contexto, en un momento en que la capital de Rio Grande do Sul atravesó un notable proceso de verticalización urbana. El artículo utiliza la recopilación, análisis y difusión de material de colección, compuesto por las etapas de fotomontaje y fotografía de la construcción del edificio Formac, que fue donado al Centro Universitário Ritter dos Reis por el propio fotógrafo, y que constituye un importante registro de la historia de la fotografía y arquitectura gaucha y brasileña, así como un patrimonio cultural inédito en Rio Grande do Sul. Con ello, se espera colaborar en la difusión de la colección fotográfica de João Alberto y en la comprensión de su producción. El fotomontaje de Formac, que aún llama la atención por su calidad técnica, expresividad y precisión, fue un elemento importante para la difusión de la naciente arquitectura moderna en el contexto local.

Palabras-clave: João Alberto Fonseca da Silva, EdificioFormac, Carlos Alberto Holanda Mendonça, arquitectura moderna, fotografía.

\section{Fotografia e Cultura Visual}

$\mathbf{N}$ o Brasil, a partir dos anos 1940, a fotografia passa por uma fase de difusão e expansão através do aperfeiçoamento das técnicas de edição e de reprodução de imagens fotográficas. Câmaras mais portáteis, como a Rolleiflex e a Leica, permitiram o avanço da foto instantânea e a presença mais dinâmica do fotógrafo no espaço público, ajudando na tarefa de documentar e informar a modernização dos espaços urbanos.

O período também foi marcado pela modernização da imprensa. O fotojornalismo atingiu o seu auge nos anos 1950 , com novas narrativas fotográficas que ocupavam cada vez mais lugar nas páginas dos jornais e re- 
2 A Revista do Globo circulou de 1929 a 1967 em Porto Alegre, com 941 fascículos e dois números especiais, um sobre a Revolução de 1930 e outro sobre a grande enchente de 1941, totalizando, assim, 943 fascículos. Disponível em: <https://ww1.pucrs.br/delfos/?p=globo> Acesso: 05 nov 20. vistas retratando, entre outros assuntos, a expansão e transformação do espaço urbano. A fotografia nas revistas ilustradas e, em especial, as fotorreportagens promoviam uma reeducação do olhar, sintetizando e ressignificando esse processo de expansão horizontal e vertical. Desta maneira, os fotógrafos passam a ser mais valorizados e a terem seus nomes mencionados como autores das imagens nessas revistas (MONTEIRO, 2012, p. 20).

Atenta às novas possibilidades de uso das imagens fotográficas, a imprensa prontamente ampliou a atuação da fotografia como documento social. A fotorreportagem impôs-se como um novo modelo de jornalismo, contribuindo para encurtar o caminho entre a leitura e a apreensão das informações. O grande diferencial, no caso, é a ênfase na imagem fotográfica, que passou a ter o mesmo valor do texto verbal, até então dominante. Em uma reportagem tradicional, o eixo central de organização das ideias está apoiado no texto, ao qual podem ser acrescidos elementos visuais como ilustrações de forma complementar. A fotorreportagem quebra com esse padrão estético, trazendo a fotografia para o centro da organização do discurso (MEYRER, 2010, p. 198-199).

Com a ampliação do uso da fotografia nos periódicos, a imprensa passou a fazer a cobertura de eventos importantes. Como exemplo, podemos citar o periódico quinzenal "Revista do Globo"2 um dos mais relevantes meios de difusão da fotografia em Porto Alegre, que retratou eventos como a Revolução de 1930, a Exposição de 1935 e a enchente de 1941 (MASSIA, 2008, p.60).

Ao congelar fragmentos de temporalidade, a fotografia permitiu condensar e recriar uma nova imagem das cidades brasileiras em mutação, ainda mais no momento em que registrou a destruição de locais tradicionais e a criação de espaços modernos. As revistas, através das fotorreportagens, cumpriam a tarefa de informar e difundir a imagem moderna da cidade e da cultura urbana para a população brasileira. Permitiam, também, a difusão de toda uma nova cultura social, com parâmetros de civilidade e de consumo que passariam a ser almejados e buscados pelos leitores desses periódicos, ávidos em participar da modernidade.

No que se refere às representações da cidade, observa-se que os recortes do espaço retratados pelas revistas nos anos 1950 eram normalmente os centros das cidades, representados por meio de ângulos abertos sobre as principais ruas e avenidas. Essas imagens 


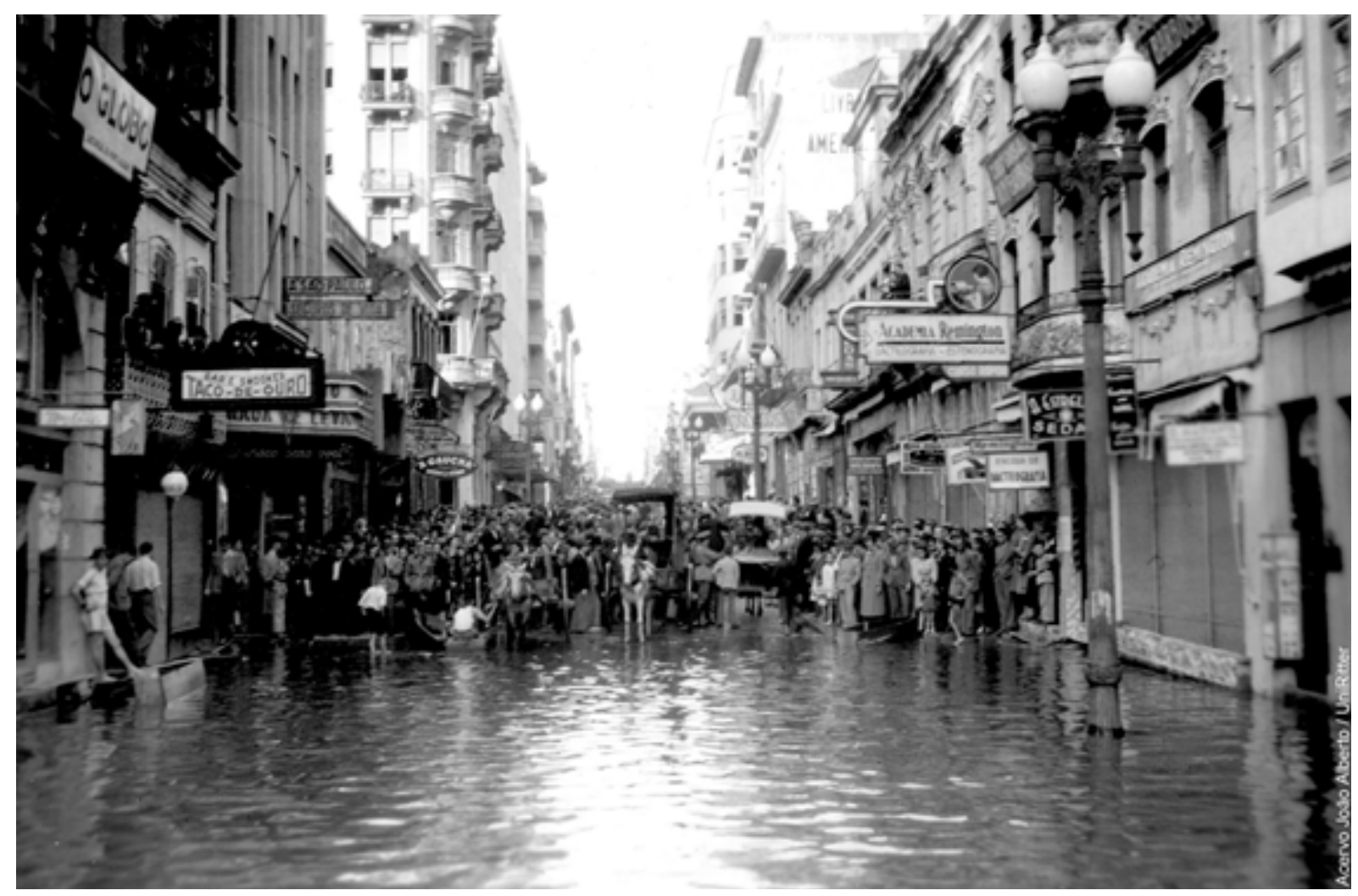

Figura 01

Rua da Praia durante a enchente de 1941 em Porto Alegre

Fonte: Acervo João Alberto Fonseca da Silva/UniRitter

ajudam a destacar o processo de verticalização da cidade através da construção de prédios altos, os quais auxiliavam na construção da percepção de uma nova escala de crescimento e de desenvolvimento.

Essa narrativa, além de auxiliar no processo de construção de uma nova visualidade para as cidades, começou a ser utilizada como uma importante ferramenta para o planejamento de obras públicas e o controle do seu espaço. No Brasil, foi no contexto do Estado Novo que a fotografia ganhou maior espaço com essas atribuições. Em nível federal, destaca-se a contratação de fotógrafos - todos estrangeiros - para o Departamento de Imprensa e Propaganda, os Serviços de Proteção ao Índio e para o Instituto do Patrimônio Histórico Cultural. Em finais dos anos 1940, o IBGE também passou a trabalhar com fotógrafos profissionais, com vistas a documentar a geografia humana das regiões periféricas do Brasil (MONTEIRO, 2012, p. 52).

Em Porto Alegre, a modernização ganha visibilidade midiática através das imagens de grandes obras públicas e da abertura de novas avenidas, bem como da construção de escolas. Frente às rápidas mudanças em curso na paisagem da capital gaúcha, decorrentes 
${ }^{3}$ A aerofotogrametria é uma técnica que permite o levantamento de extensas áreas, que são fotografadas e posteriormente transformadas em cartas topográficas, equivalentes a mapas que indicam as condições do terreno: formações naturais, localização de cidades, curso dos rios etc. Ver: MONTEIRO, Charles (Org.). Fotografia, história e cultura visual: pesquisas recentes. Porto Alegre: EDIPUCRS, 2012, p. 52 do cada vez mais acelerado processo de verticalização da cidade, a imprensa passou a utilizar as fotografias para destacar as novas práticas políticas do Estado. Levantamentos fotográficos aéreos e terrestres apontam tanto para a expansão da malha viária quanto para o uso da imagem fotográfica com o objetivo de gestão do espaço urbano. O fotógrafo João Alberto Fonseca da Silva acompanhou de perto o processo de modernização da área central de Porto Alegre, sendo o autor de um relevante levantamento fotográfico da cidade.

\section{João Alberto Fonseca da Silva e o retrato da modernidade}

João Alberto Fonseca da Silva é natural de Quaraí, cidade localizada próxima à fronteira com o Uruguai e a Argentina. Quando chegou à época de servir ao exército, mudou-se para Porto Alegre com o intuito de tentar melhores condições de vida. Foi quando teve a oportunidade de trabalhar como laboratorista do Serviço Geográfico do Exército, ocasião em que aprendeu as técnicas de revelação e de composição de cartas em aerofotogrametria ${ }^{3}$.

Com o aprendizado obtido neste tipo de processo técnico em fotografia e com as amizades que fez em sua passagem pelo exército, João Alberto ingressou na Secretaria Estadual de Obras Públicas em 1939, permanecendo lá até a década de 1950. Dentro desta Secretaria, existia a Diretoria de Saneamento e Urbanismo, subseção na qual João Alberto era encarregado de fotografar as inaugurações das obras públicas do Estado e de fazer levantamento fotográfico das áreas que receberam melhorias no abastecimento de água e tratamento de esgoto.

Em conjunto com o trabalho no Setor de Obras Públicas, João Alberto começou a produzir outros tipos de fotografia. Como o cargo de fotógrafo do departamento passou a ser desempenhado em meio turno, João Alberto buscou alternativas para aumentar seus rendimentos e, assim, aprendeu outras possibilidades do ofício. Fotografou casamentos, confeccionou lembranças de aniversário e atuou como artista-fotógrafo. Neste contexto, duas áreas foram de extrema importância para os trabalhos de João Alberto: a publicidade e a arquitetura.

A publicidade surgiu na sua carreira por meio do aperfeiçoamento das técnicas de ampliação e redução decorrentes de sua experiência na produção dos aerolevantamentos. Logotipos e imagens podiam ser 
justapostos e diagramados, algo que era comum na imprensa. A publicidade, como ramo da fotografia, exige do fotógrafo grandes habilidades técnicas, impondo um desafio a João Alberto: enxergar, com exatidão e simetria, características que apontam para um olhar típico da época e que encontravam espaço em áreas como a publicidade, o design gráfico, as artes plásticas e, também, a arquitetura.

Porém, foram os trabalhos para as construtoras e para os escritórios de arquitetura e engenharia que se tornaram os mais relevantes na produção do fotógrafo. $A$ partir de 1950, à medida que suas habilidades profissionais evoluíam, o relacionamento com arquitetos e engenheiros cresceu, e estes se tornaram seus clientes habituais. Obras de renomados arquitetos gaúchos, tais como Carlos Alberto de Holanda Mendonça, Ari Mazini Canarin, Irineu Breitman, Edgar Albuquerque Graeff, Claudio Luiz Araújo e Carlos Maximiliano Fayet foram fotografadas por João Alberto. Suas fotos também registram a execução de muitas obras da construtora Azevedo Moura \& Gertum, algumas delas hoje consideradas patrimônio arquitetônico da cidade de Porto Alegre ${ }^{4}$, nas quais se procura exaltar a técnica e o sentido da construção no projeto, tão importantes para a modernidade arquitetônica gaúcha.

As suas fotografias de arquitetura exerceram grande influência no fotojornalismo em ascensão nos anos 1950. As imagens fotográficas tinham um forte apelo por apresentarem a modernização e o crescimento das cidades gaúchas, sendo muito utilizadas pelas revistas. Dessa forma, João Alberto acabou sendo o responsável pela documentação do processo de transformações arquitetônicas e urbanísticas ocorridas em Porto Alegre entre as décadas de 1950 e 1970.

Graças ao seu saber técnico, João Alberto utilizou-se de inovações como a fotomontagem ${ }^{5}$ e os serviços de redução, tendo sido desafiado a fazer a inserção de maquetes de edifícios em fotografias do espaço da cidade. Após observar o local de construção do prédio, fotomontava a maquete no terreno destinado ao projeto, de modo que a imagem se constituía em um documento no qual era possível visualizar a presença da futura construção. Cabe ressaltar aqui que esse tipo de imagem, com grandes efeitos de realismo, tinha uma circulação bastante ampla, além de cumprir funções técnicas e estéticas, sendo veiculada tanto em revistas quanto em grandes painéis fotográficos.

As fotografias de arquitetura obedeciam a padrões simétricos, de proporções calculadas, exploração dos
4 Foram executadas pela Azevedo Moura \& Gertum obras como o Hipódromo do Cristal, os edifícios Guaspari, Imperial, Jaguaribe, Esplanada e Sulacap.

5 Fala-se de inovação aqui somente em termos locais. A fotomontagem em arquitetura já era utilizada desde o início do século XX: em 1918, Mies van der Rohe apresentou-a no projeto dos arranha-céus na Friedrichstrasse; depois, em 1921, nos novos edifícios na Alexanderplatz e, em 1927, Ludwig Hilberseimer utilizou-as em seus projetos para o centro de Berlim (SOLA-MORALES, 2008). 
efeitos de tridimensionalidade, equilíbrio e nitidez. Em síntese, a fotomontagem de arquitetura pretendia ser um espelho da realidade futura, com a inserção dos prédios no espaço urbano como forma de avaliar e divulgar suas qualidades estéticas em meio ao conjunto da cidade. Na apresentação dos projetos arquitetônicos, além da fotomontagem, dossiês eram elaborados com a presença de plantas das edificações, as quais eram fotografadas e reduzidas para serem visualizadas em sua integralidade. Era mais um recurso visual que contava com o desenvolvimento de um saber técnico baseado na precisão.

Como é possível observar, a trajetória de João Alberto confunde-se com a própria história da fotografia e da arquitetura em Porto Alegre. Muitas vezes o fotógrafo precisou achar suas próprias soluções para as ideias apresentadas, como no caso de sua primeira fotomontagem, que será abordada mais adiante. Do ponto de vista da estética, sua obra não se encontra isolada. Porém, mais importante do que localizar a imagem do ponto de vista da técnica, seria conhecer as condições sociais de produção da obra.

A busca da compreensão a partir desse enfoque é possível a partir da consulta e análise de uma parte do acervo de João Alberto, que foi doado pelo próprio fotógrafo ao Centro Universitário Ritter dos Reis em 1997. O rico acervo reúne mais de 12 mil negativos de vários formatos, além de aerofotos, álbuns fotográficos e painéis, que registram exemplares de arquitetura, paisagens, aspectos urbanos e regionais do Rio Grande do Sul, além de obras de publicidade, design, artes gráficas e retratos. Na área da arquitetura, o acervo fotográfico compreende desde imagens de desenhos técnicos e perspectivas até registros fotográficos de edificações, obras em construção e interiores, inclusive de eventos sociais relacionados à arquitetura.

Em seu trabalho com arquitetos, engenheiros e construtoras, João Alberto, graças a um olhar sensível e único, desenvolveu empiricamente uma série de técnicas fotográficas com o objetivo de integrar a arquitetura com a fotografia. O fotógrafo atuou em caráter profissional até a década de 1980 , vindo a falecer no ano de 2011.

\section{O projeto do Edifício Formac}

A primeira fotomontagem de arquitetura realizada por João Alberto foi feita sob encomenda do arquiteto Carlos Alberto Holanda Mendonça, que, no início da 
década de 1950, estava projetando um edifício moderno na área central de Porto Alegre. Vale ressaltar que, entre 1930 e 1950, a cidade transformou radicalmente sua aparência, passando de uma matriz arquitetônica eclética para uma capital moderna. Foi nesse contexto de modernização do centro de Porto Alegre, "incentivado por uma imagem favorável, que associava os edifícios altos ao progresso e ao moderno, tanto em termos figurativos quanto na ilustração de um novo modo de vida" (ABREU FILHO, 2016, p. 238), que Mendonça projetou, em $1952^{6}$, sob encomenda da empresa Predial Formac Ltda, um dos primeiros edifícios modernos de grande porte da capital - o Edifício Formac.

Mendonça teve um papel relevante na transformação de Porto Alegre ao colaborar para a afirmação de uma arquitetura que até hoje permanece como exemplo de qualidade técnica e estética, isto em uma época bastante produtiva no campo da construção e do desenvolvimento da cidade. Apesar de sua curta carreira de somente uma década, é atribuído ao arquiteto o mérito de ter colaborado para a inserção do vocabulário moderno com influência corbusiana na cidade de Porto Alegre, ao "iniciar uma arquitetura moderna local com pedigree, alinhada conscientemente com os enunciados e doutrinas das vanguardas europeias" (LUCCAS, 2004, p. 12).

O Edifício Formac está localizado no centro histórico de Porto Alegre, na região que fica entre o Mercado Público e a Praça da Alfândega, ainda hoje considerada um importante polo comercial (Figura 02). O terreno de esquina onde se situa o edifício faz frente para a Avenida Mauá e para a Travessa Francisco Leonardo Truda. Atualmente parte da primeira Perimetral de Porto Alegre, a Avenida Mauá já era, na época, uma importante via de acesso à área central, sendo ainda a interface da cidade com a área portuária (Cais Mauá). A Travessa Francisco Leonardo Truda, por sua vez, era uma via de abertura recente que conectava a Av. Mauá à Rua Siqueira Campos.

No projeto aprovado pela Prefeitura Municipal, o edifício é um volume prismático de 26 pavimentos, com uma organização volumétrica tripartida - composto de base, corpo e coroamento - nos moldes canônicos da arquitetura moderna carioca. Seu programa original contava com comércio na base, escritórios do $3^{\circ}$ ao 170 pavimento, apartamentos entre este e o $24^{\circ}$ e, nos dois últimos pavimentos, um restaurante e uma casa de shows. A possibilidade de atingir a altura de 26 pavimentos teria sido dada pela municipalidade em
6 Como detalha BUENO (2002, pág. 155 a 163), o projeto do Formac teve a sua primeira versão protocolada para aprovação na Prefeitura Municipal de Porto Alegre em março de 1952, ao passo que a sua aprovação, com versão modificada, data de dezembro do mesmo ano. 


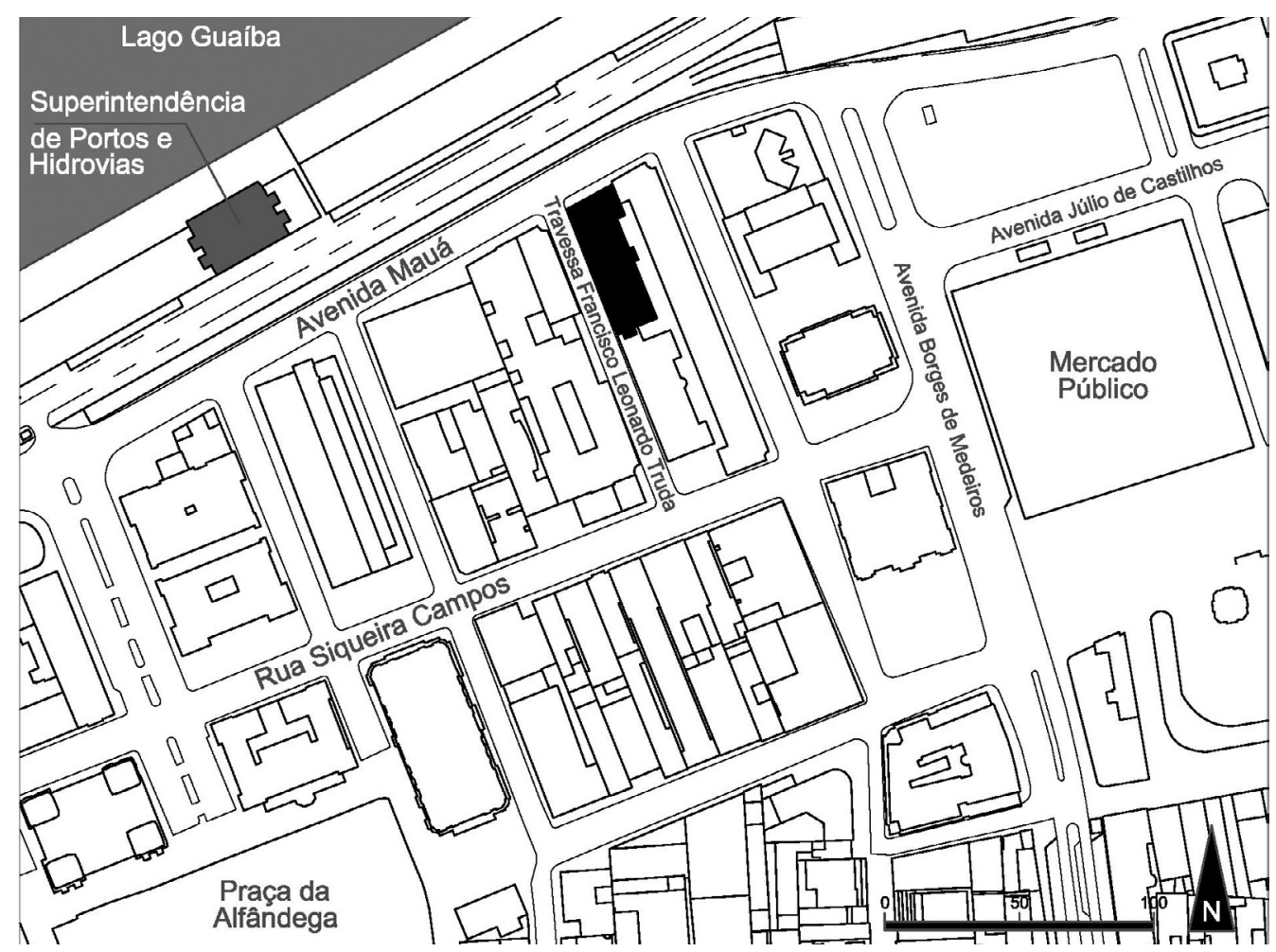

Figura 02

Situação do Edifício Formac na porção central de Porto Alegre Fonte: Autores

compensação pela desapropriação de parte do terreno original para a abertura da Travessa Leonardo Truda, "resultando em um volume edificado com dimensões impressionantes para a época" (XAVIER \& MIZOGUCHI, 1987, p. 97).

A base ocupa todo o terreno, e consiste em um volume transparente com dimensões aproximadas de 50 metros de largura por 16 metros de profundidade, sendo recuada em relação ao volume do corpo e expondo a estrutura em pilotis na face mais alongada, colunata de duplo pé-direito, que dá para a Travessa Leonardo Truda. O recuo do fechamento de vidro em relação à linha de colunas, na fachada da travessa, cria um espaço linear de transição entre o público e o privado, além de marcar o acesso principal ao edifício.

O arredondamento do fechamento da esquina, na base, reforça o encaminhamento de quem transita pela Avenida Mauá - via de maior tráfego - ao acesso principal pela travessa. O ingresso ocorre pelo vão central, com pé-direito duplo, onde se encontram a recepção e o hall de elevadores. As laterais são ocupadas por espaços de comércio com mezaninos, cujos acessos se dão tanto pelo núcleo de circulação vertical coletivo quanto por escadas privativas. Externamente, é possível ver a marcação horizontal do mezanino na fachada. 
O corpo, um volume prismático de aproximadamente 53 metros de largura por 20 metros de profundidade e 72 metros de altura, abriga as funções de escritório e moradia. Essa diferença funcional é trabalhada de forma sutil nas fachadas principais. As empenas recebem tratamento distinto, dependendo da orientação solar e da hierarquia - as fachadas norte e oeste, que são as principais, recebem maior atenção nas soluções empregadas.

Na fachada norte, voltada para a Av. Mauá, uma greIha fixa recebe brises horizontais, à maneira do Ministério da Educação e Saúde, no Rio de Janeiro (1936). A grelha fixa abriga variações necessárias: nos pavimentos de escritório, o peitoril acompanha a linha do volume principal e, nos pavimentos de apartamentos, o peitoril avança para se alinhar com a face externa da própria grelha. Na fachada oeste, mais atingida pela insolação, uma grelha quadrada, constituída pelo vão de pilares e pela altura de um pavimento, abriga brises verticais. Proposto dentro da lógica do quarteirão tradicional, a fachada sul e parte da leste estão coladas às divisas do lote. Apesar da maior parte da fachada leste abrir-se para o pátio alongado e estreito, esta não recebe o mesmo investimento das demais, sendo tratada pela disposição funcional e regular de aberturas de janelas.

O coroamento, que aloja o restaurante e a casa noturna, é feito por meio de uma transformação do volume do corpo. Na parte norte, a grelha fixa ganha uma dupla altura e uma dupla quantidade de brises. Na fachada oeste, o coroamento aparece tripartido, o vão central repete a solução dos brises verticais do corpo e, nas extremidades, onde não há a necessidade dos brises, acrescentam-se peitoris que servem de varandas para o restaurante. A simetria e o ritmo dessa tripartição do coroamento são forçadas pela supressão do último módulo, na extremidade sul.

A técnica construtiva é o concreto armado com vedações em alvenaria. De planta livre, a distribuição das colunas na fachada menor, voltada para a Avenida Mauá, dispõe de dois vãos regulares de 7,5 metros de eixo, com um vão menor de 3,65 metros junto à fachada leste e balanço de aproximadamente 1 metro para a fachada oeste, a principal. Ao longo da fachada principal, são dispostos sete vãos de 7 metros de eixo e um vão variável, menor, junto à fachada norte, que fica em balanço próximo à esquina. Essa organização estrutural garante a clareza da solução adotada e a flexibilidade dos espaços. 
O Edifício Formac, apesar de não ser um modelo de qualidade arquitetônica excepcional, está inserido no contexto de uma produção de capital de província periférica que Comas reconhece ter "planejamento competente e muitos acertos" e no qual predominam "comedimento e aplicação" (COMAS, 2013, p. 23).

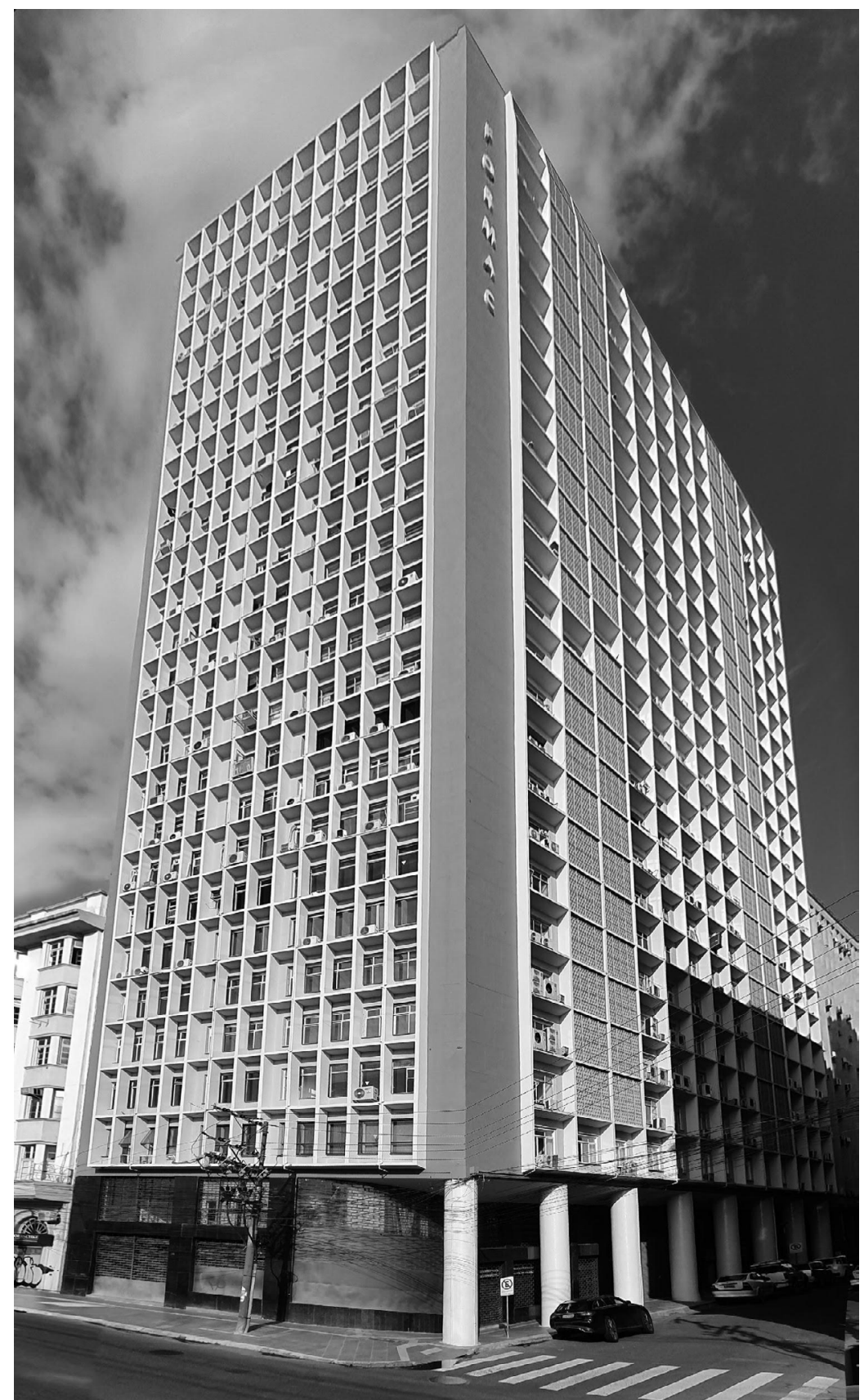

Figura 03

Situação atual do Edifício Formac

Fonte: Autores

Mesmo assim, o projeto carrega adequados desenvolvimentos das proposições do vocabulário da vanguarda moderna brasileira em terras de notável cultura conservadora, reafirmando inovações importantes. Isso se evidencia na utilização de elementos moder- 
nos, como a composição volumétrica tripartida, o rigor estrutural, o tratamento das fachadas, a colunata de duplo pé-direito e a busca da transparência do térreo, mesmo sendo uma encomenda que se adequava tanto ao mercado imobiliário quanto a um terreno em quadra tradicional.

A conclusão da obra do Edifício Formac ocorreria somente no início da década de 1960 , e o resultado construído apresenta alterações consideráveis em relação ao projeto aprovado na Prefeitura de Porto Alegre em dezembro de 1952 (Figura 03). O arranjo geral do edifício é mantido em planta e o seu uso, anteriormente misto, foi destinado somente a escritórios. Porém, são as elevações que apresentam as alterações mais marcantes, através de uma simplificação empobrecedora da solução adotada. Na fachada oeste, parte dos brises verticais foi substituída por painéis de cobogós e a outra parte foi simplesmente suprimida. A grelha quadrada de um pavimento de altura manteve a unidade da fachada, mas as faixas de cobogó, posicionadas para esconder sanitários dos pavimentos das salas comerciais, não geram ritmo e não protegem do sol oeste os compartimentos de permanência. $\mathrm{Na}$ fachada norte, a grelha fixa também foi mantida, mas sem a presença dos brises horizontais.

Cabe ressaltar que não há registro de que essas alterações tenham partido de decisão do arquiteto Carlos Alberto de Holanda Mendonça. Talvez em função disso, a fotomontagem de João Alberto compareça fortemente nos registros da arquitetura local, tendo sido, inclusive, apresentada na clássica antologia "Arquitetura Moderna em Porto Alegre" de Xavier e Mizoguchi (1980).

\section{A fotomontagem do Edifício For- mac}

Não bastando o pioneirismo do projeto na carreira de Mendonça e a sua relevância para a cidade, o Edifício Formac seria também a primeira fotomontagem feita no Estado, através da encomenda a João Alberto. O pedido de Mendonça ao fotógrafo consistia em fazer a inserção da maquete ${ }^{6}$ do edifício no terreno onde ele seria construído. Conforme o relato do fotógrafo:

(...) surgiu a famosa fotomontagem, que tinha um arquiteto que gostava muito de novidade, era muito ilustrado que era um arquiteto formado no Rio. (...) O Mendonça quis fazer uma fotomontagem de um edifício, chegou, deixou a maquete na minha casa, com um bilhetinho: "Fazer fotografia da maquete e fazer uma fotomontagem da maquete" em tal lugar assim. Esse foi o edifício Formac. Aí eu ri, eu nunca disse
${ }^{6}$ A maquete foi produzida por Percival José Gonzaga da Silva, que tinha sido desenhista de Mendonça. Ver: BUENO (2012, p. 105). 
que fazia fotomontagem. Mas depois tava tomando meu chimarrãozinho em casa depois do banho e fiquei pensando, mas digo, eu não disse que fazia, mas podia ir lá olhar né. Aí vinha eu, olhei o local e bati uma foto. E acabei montando a fotomontagem e foi a minha primeira fotomontagem foi do edifício Formac (SILVA apud MASSIA, 2008, pág. 110-111).

Apesar de informativo, o depoimento de João Alberto não esclarece a respeito dos aspectos técnicos de produção dessa fotomontagem. Conforme Canez et al, João Alberto utilizou uma série de técnicas fotográficas pouco usuais naquele momento, como a distorção da perspectiva, fotomontagens, separação de tons, solarização e retícula aplicada. O fotógrafo lançou mão de um equipamento composto por câmeras e lentes específicas, além de "negativos de vidro de grande formato e com equipamentos que possibilitaram a correção da perspectiva dos edifícios" (CANEZ et al, 2004, p. 130).

Analisando as fotografias, pode-se dizer, com alguma segurança, que aquela da paisagem de rua, utilizada como base para a sobreposição da maquete (Figura 04), foi feita, a partir da cobertura do edifício da Superintendência de Portos e Hidrovias, de uma distância de aproximadamente 110 metros da esquina do

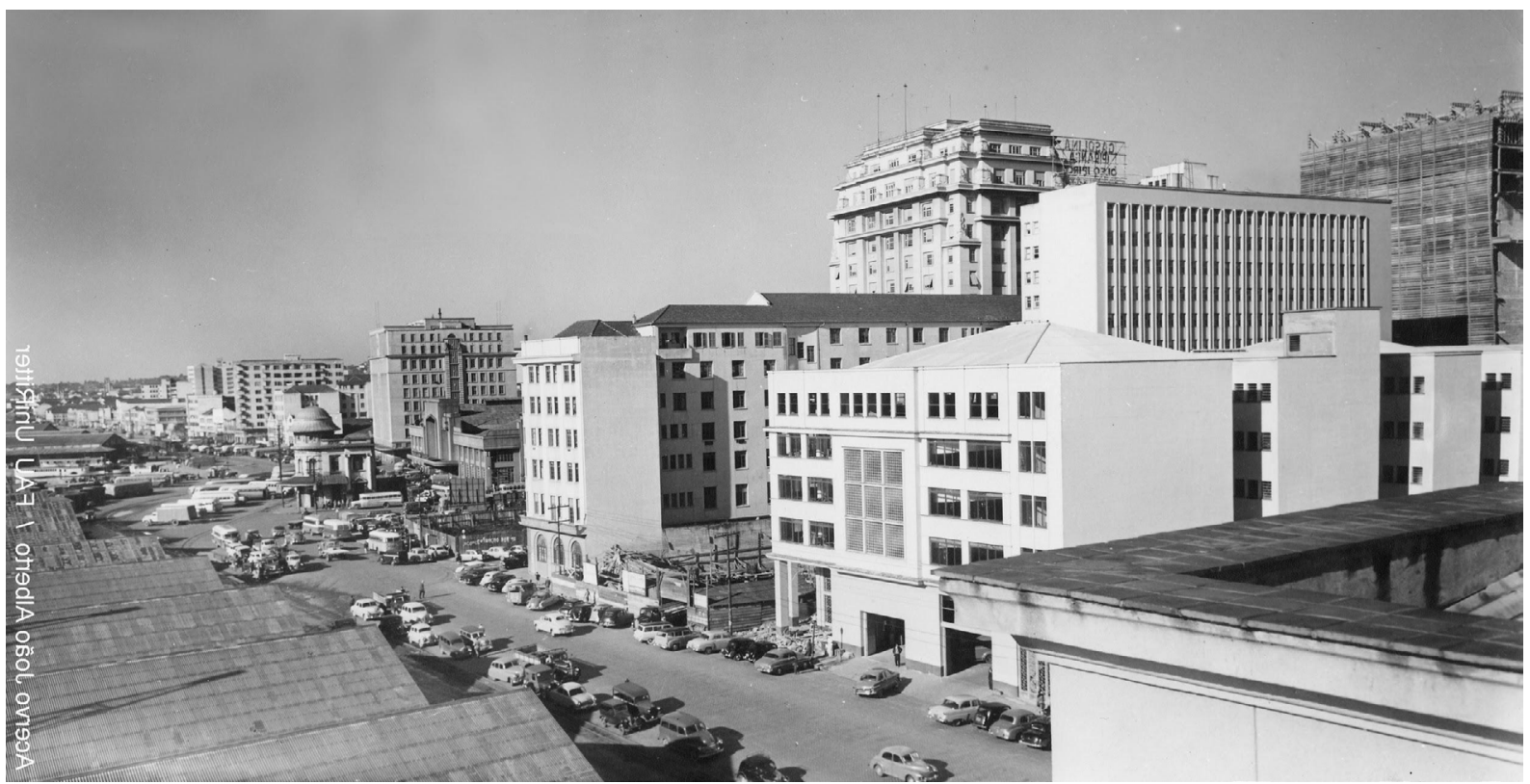

Figura 04

Fotografia da cena do terreno onde seria construído o Edifício Formac Fonte: Acervo João Alberto Fonseca da Silva/UniRitter

lote e a uma altura de aproximadamente 20 metros. A distância, a altura da posição e o equipamento adequado garantiram a correção das linhas verticais da 
foto original. O ponto de vista também fornece alinhamento das coberturas do entorno imediato com a linha do horizonte. A insolação sudoeste foi selecionada para destacar as fachadas do Formac e para garantir o contraste das sombras.

A fotografia da maquete (Figura 05) é obra de estúdio, e, possivelmente, foi registrada com lente de correção de perspectiva para depois ser reduzida e recortada. A escolha do ponto de vista ressalta as duas fachadas principais do Formac, ao passo que o cuidado se volta para demonstrar a rugosidade dos brises e a coincidência para com o sombreamento da foto base.

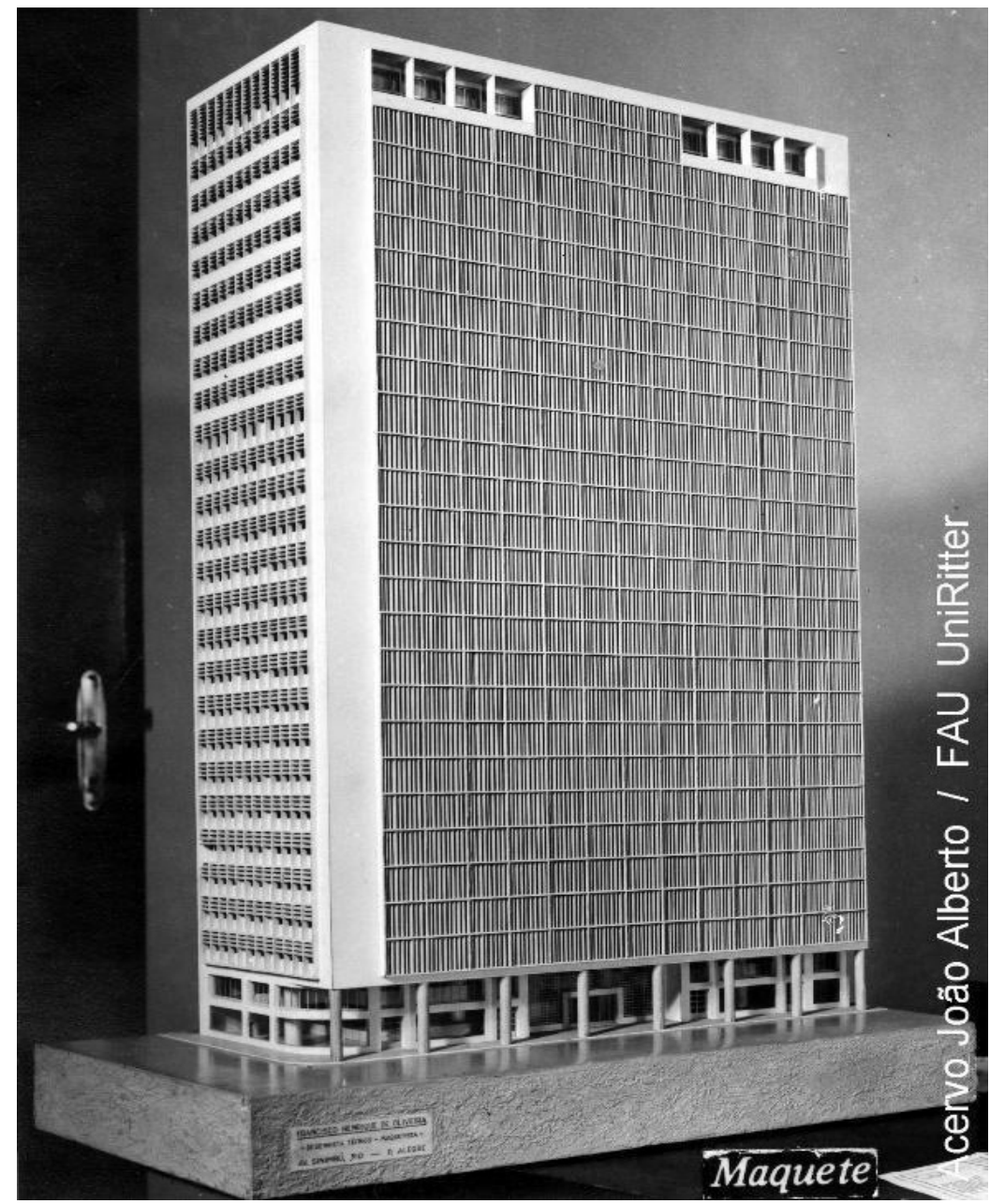

Figura 05

Fotografia da maquete do projeto do Edifício Formac

Fonte: Acervo João Alberto Fonseca da Silva/UniRitter

No entanto, comparando os originais e a fotomontagem, percebe-se que não se trata de simples sobreposição. O formato da imagem mudou para comportar a altura do Formac, assim como foi inserido um céu nublado para oferecer profundidade à perspectiva. Alguns detalhes também foram trabalhados: pessoas inseridas na calçada para dar noção de escala, ajuste da 
posição de um carro da rua e recorte da presença de alguns andaimes de obra no alto à direita. O resultado exalta a altura do Formac e o contraste de sua abstração formal frente ao entorno, que também sinalizava transformações. A imagem respondeu à demanda por realismo com equilíbrio de proporções, em um tipo de representação tecnicamente precisa, mesmo que produzida, em grande parte, a partir do olhar humano.

A fotomontagem causou impacto ao ser exposta na Casa Comercial Herrmann, situada na esquina da Rua dos Andradas com a Uruguai. Esse fato data de 1953 ou 1954, conforme o relato do fotógrafo. A casa em questão vendia materiais fotográficos, relógios e joias. Por causa das suas relações de amizade com o dono do estabelecimento, João Alberto deixou a fotomontagem exposta na vitrine. O fotógrafo relata alguns dos comentários feitos pelos transeuntes. Uma das falas que ficou marcada na memória de João Alberto foi que a cidade na imagem não deveria ser Porto Alegre e muito menos que tivesse sido feita por um fotógrafo local. Conforme o relato do fotógrafo:

(...) como o Mendonça era muito noveleiro como a gente chamava, gostava de novidade, ele quis fazer uma ampliação grande. Então eu fiz uma ampliação, se não me engano, era noventa por sessenta do trabalho dele já fotomontado. E porque eu andava muito na Casa Hermann, botamo na vitrine da casa Hermann (...) na esquina da rua Uruguai com a rua dos Andradas. E aí até foi curioso. Pena que eu não tinha gravador como vocês tem agora, porque o que se ouvia de coisas engraçadas daquele público que olhava (...). Então não era feito em Porto Alegre. (...) Mas o importante da história é que se comentava, a fotografia daquele tamanho já tinha vindo dos Estados Unidos, pra começar. E o Braga que era da Casa Hermann mandou um dia escutar, e eu fui escutar, fiquei no meio do povo ali escutando e se comentava coisas engraçadas, entre elas que o edifício não era em Nova York, que era em tal cidade, que tinha um sabido lá. Porque o edifício aqui em Porto Alegre não tinha um edifício, parece que são vinte e poucos andares.(SILVA apud MASSIA, 2008, pág. 110-111).

A questão relevante do depoimento acima é que João Alberto teve a oportunidade de relatar situações não só sobre a circulação da obra, mas a respeito de sua recepção. A fotomontagem servia muito bem ao processo de planejamento, e sabe-se de seu uso pelo corpo técnico do Estado. Ao inserir a maquete do edifício em plena área central da cidade, ainda predominantemente horizontal, o fotógrafo causou um choque visual, pois uma imagem tida como reflexo da realidade estava ali e já criava ficções, conforme é possível observar em seu produto final (Figura 06).

Claro está, também, que a fotomontagem hoje não causa o mesmo espanto. Em decorrência do avanço das tecnologias disponíveis para simular a realidade, 


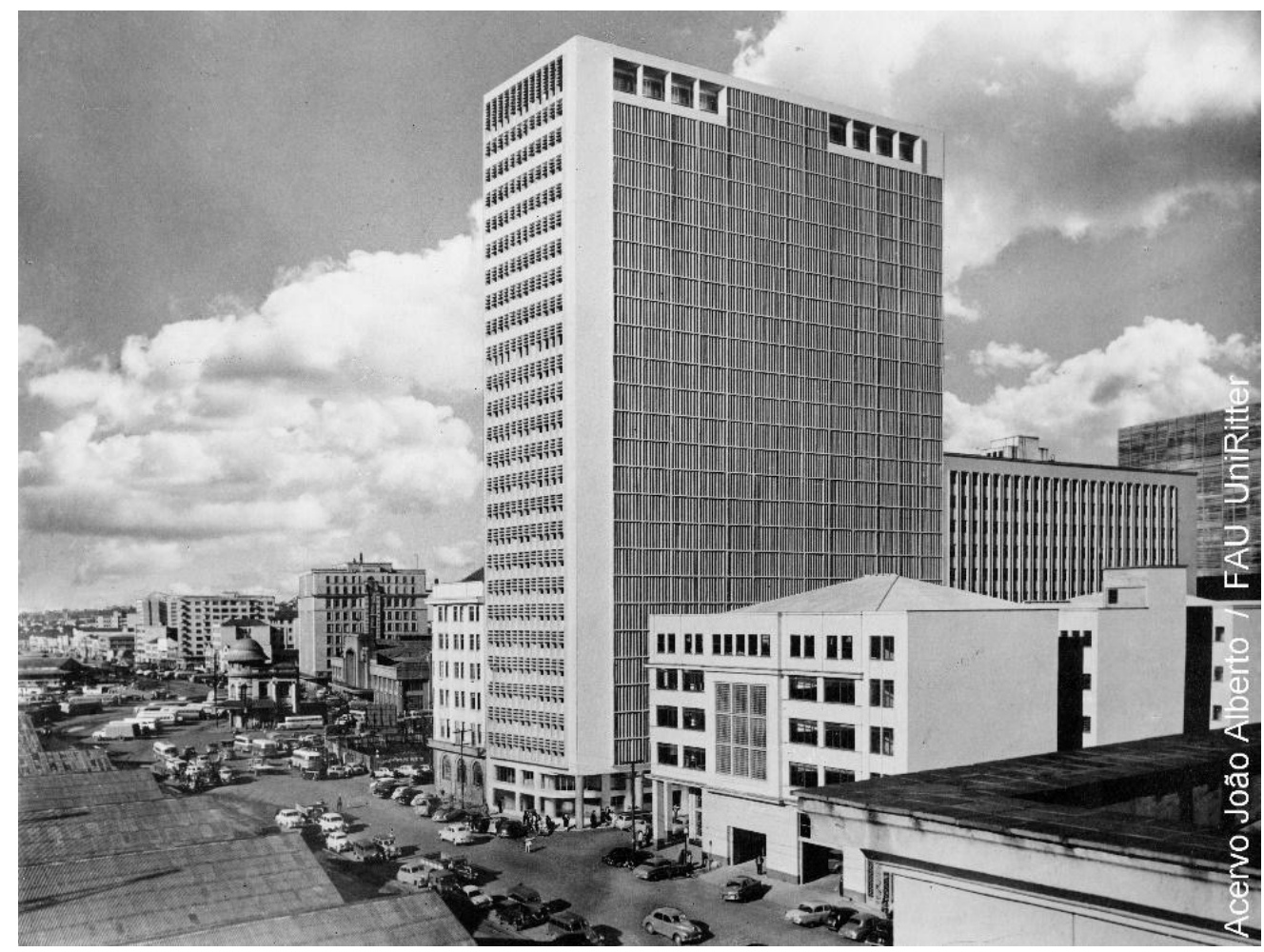

Figura 06

Fotomontagem do Edifício Formac

Fonte: Acervo João Alberto Fonseca da Silva/UniRitter

a sociedade atual já saturou o olhar em relação a esse tipo de imagem. Contudo, não podemos esquecer que, na época, as principais referências em termos de modernização eram as grandes cidades norte-americanas ou europeias oriundas de cartões-postais ou de fotografias impressas em revistas ilustradas.

Se, em períodos anteriores, a modernidade era vista como algo a ser alcançado no futuro, na década de 1950 existia a sensação de que tal futuro havia chegado de forma definitiva (MONTEIRO, 2012, p. 57). Nesse contexto, o papel da fotografia, considerada aqui como um dispositivo que mediava também a questão do crescimento urbano, exercia papel fundamental no planejamento de ações futuras, sem contar o fato de que apresentava a cidade como um índice concreto da modernização do país.

É lícito dizer que a trajetória do fotógrafo foi construída a partir dos desafios que lhe foram lançados em termos visuais. O êxito ocorreu pela insistência e pelo treinamento do olhar, de acordo com uma visão tecnicista que predominava na arquitetura. As suas fotografias e fotomontagens tinham um forte apelo de veracidade ao apresentar a modernização e o crescimento de Porto Alegre, sendo utilizadas, inclusive, 
pelas revistas ilustradas. A trajetória de João Alberto confunde-se com a própria história da fotografia, assim como as suas fotos são um poderoso instrumento no sentido de interpretar a obra arquitetônica, seja pela captura da realidade na qual se inseriam, seja pela manipulação desta realidade.

\section{Considerações Finais}

A imagem fotográfica tem o poder de influenciar a interpretação da arquitetura e pode até mesmo repercutir no ato de projetar, devido ao seu inegável poder de manipulação da realidade. Apesar de, mesmo no contexto atual, manter a reputação de ser um registro fiel da realidade, a fotografia que faz uso especializado das técnicas de captura de imagem é capaz de produzir registros interpretativos e, por consequência, provocar percepções estimuladas - ou alteradas - no receptor da imagem final. Mediante a associação das técnicas de captura com as de fotomontagem, é possível deixar a manipulação da produção de imagens ainda mais efetiva, chegando ao ponto de produzir uma realidade completamente diferente.

Neste sentido, a fotografia como representação arquitetônica pode ser entendida na qualidade de uma das formas de representação do objeto. Da mesma maneira que qualquer outro tipo de imagem, as fotografias são mais do que apenas um meio de comunicação. Nelas está contido um modo de ver particular de cada autor, bem como a sua visão, suas impressões e aquilo que ele quer mostrar, além daquilo que foi contextualmente adquirido por ele como memória coletiva. Desta forma, o fotógrafo funciona como um filtro da realidade, expressando-se com intensidade própria.

A fotomontagem de João Alberto para o Edifício Formac apresenta uma dimensão histórico-espacial capaz de expressar o que era, então, uma possibilidade de futuro para Porto Alegre. Poderíamos até mesmo afirmar que a fotomontagem manifesta, através dessa capacidade de paralisação do tempo e de uma consequente relação passado-presente-futuro, uma realidade possível, mas que seria alterada com as posteriores modificações do projeto.

A participação da fotografia no registro e na divulgação da arquitetura moderna do século XX alterou para sempre a sua relação com os processos de produção e difusão do conhecimento arquitetônico. Essa relação induziu a uma forte dependência da representação do espaço arquitetônico, desconectando a fotografia de 
um valor meramente documental ao mesmo tempo em que a aproximava dos meios de comunicação e representação artística. É neste sentido que a participação de João Alberto no registro da arquitetura moderna, bem como através da elaboração de fotomontagens que simulam com virtuosismo a inserção de um edifício projetado, mescla técnica e arte, instituindo, em terras locais, um processo de representação e difusão da obra arquitetônica até então inédito.

O Edifício Formac cumpriu, assim, um papel que vai além da sua própria materialização arquitetônica. A fotomontagem realizada pelo fotógrafo João Alberto que, na época de elaboração e divulgação, já provocou alvoroço na cultura local - ainda hoje chama atenção pela qualidade técnica, expressividade e precisão. As qualidades arquitetônicas do edifício (e as qualidades formais do projeto original), méritos do arquiteto Carlos Alberto de Holanda Mendonça, certamente contribuíram para a perenidade dessa imagem.

Contudo, o trabalho do fotógrafo ao reforçar as boas qualidades do projeto, que serviu para promover o objetivo inicial da venda do empreendimento, divulgou a arquitetura moderna como uma nova linguagem para o mercado imobiliário e para a sociedade da época. Ao fim, o trabalho promoveu não só o Edifício Formac como objeto de arquitetura, mas serviu ainda como peça de difusão da arquitetura moderna no Rio Grande do Sul. A imagem também popularizou uma versão idealizada da modernidade local que nunca chegou a se concretizar, visto que o edifício construído não corresponde à imagem montada e, talvez, tenha sido mais influente que o próprio objeto o qual tentou representar.

\section{Referências}

ABREU FILHO, Silvio Belmonte de. Vertigem das alturas. In FIORE, Renato Holmer (org.). Modernização e verticalização da área central de Porto Alegre. Porto Alegre: Marcavisual, 2016.

BUENO, Marcos. A obra do arquiteto Carlos Alberto Holanda Mendonça. Dissertação (Mestrado) - Universidade Federal do Rio Grande do Sul. Faculdade de Arquitetura e Urbanismo. Programa de Pós-Graduação em Arquitetura, Porto Alegre, 2012.

COMAS, Carlos Eduardo. Confronto. In COMAS, Carlos Eduardo; PIÑON, Helio. Inventário da arquitetura moderna em Porto Alegre- 1945/65. Porto Alegre: Marcavisual, 2013, p.1524.

CANEZ, Anna Paula (et al.) Acervos Azevedo Moura e Gertum e João Alberto: imagem e construção da modernidade em Porto Alegre. Porto Alegre: Ed. UniRitter, 2004. 
LUCCAS, Luís H. H. Arquitetura moderna brasileira em Porto Alegre sob o mito do 'gênio artístico nacional". Tese (Doutorado) - Universidade Federal do Rio Grande do Sul. Faculdade de Arquitetura e Urbanismo. Programa de Pós-Graduação em Arquitetura, Porto Alegre, 2004.

MASSIA, Rodrigo. Fotógrafos, espaços de produção e usos sociais da fotografia em Porto Alegre nos anos 1940 e 1950. Dissertação (Mestrado) - Pontifícia Universidade Católica do Rio Grande do Sul. Faculdade de Filosofia e Ciências Humanas. Programa de Pós-Graduação em História, Porto Alegre, 2008.

MEYRER, Marlise. Revista O Cruzeiro: Um projeto civilizador através das fotorreportagens. História Unisinos, V. 14, p. 197-212, 2010.

MONTEIRO, Charles (Org.). Fotografia, história e cultura visual: pesquisas recentes. Porto Alegre: EDIPUCRS, 2012.

SOLÁ-MORALES, Ignasi de. Do contraste à analogia: novos desdobramentos do conceito de intervenção arquitetônica. In: NESBITT, Kate. Uma nova agenda para a arquitetura: antologia teóriaca (1965-1995). São Paulo: CosacNaify, 2a ed. rev., 2008, p. 254-263.

XAVIER, Alberto; MIZOGUCHI, Ivan. Arquitetura moderna em Porto Alegre. São Paulo: Pini, 1987. 